\title{
EARLY POSTOPERATIVE COMPLICATIONS OF THYROID SURGERY AND THEIR MANAGEMENT
}

\author{
Vinod Kumar B1, Sheldon Mathias², John Joseph S. Martis ${ }^{3}$
}

${ }^{1}$ Assistant Professor, Department of General Surgery, Father Muller Medical College, Mangalore.

${ }^{2}$ Assistant Professor, Department of General Surgery, Father Muller Medical College, Mangalore.

3 Professor, Department of General Surgery, Father Muller Medical College Hospital, Mangalore.

\section{ABSTRACT}

\section{BACKGROUND}

Thyroid swelling is one of the most common complaint of patients presenting to the surgery outpatient department. Thyroidectomy is a common surgical procedure that has several potential complications or sequelae including temporary or permanent change in voice, temporary or permanently low calcium, need for lifelong thyroid hormone replacement, bleeding, infection, and the remote possibility of airway obstruction due to bilateral vocal cord paralysis. Complications are uncommon when the procedure is performed by an experienced surgeon. However, most of the complications are manageable. Aim of the study was to assess early post-operative complications of thyroid surgeries and their management.

\section{MATERIALS AND METHODS}

All patients who underwent thyroidectomies at Father Muller Medical College Hospital from May-December 2015 were included in the study.

\section{RESULTS}

In this study, 200 patients who underwent various thyroid surgeries were studied to look for occurrence of different early postoperative complications.

\section{CONCLUSION}

Post-operative hypocalcaemia, temporary and permanent recurrent laryngeal nerve paralysis and airway obstruction were noticed and they were successfully managed.

\section{KEYWORDS}

Recurrent Laryngeal Nerve (RLN) Paralysis, Thyroidectomy, Hypocalcaemia, Post-operative Complications.

HOW TO CITE THIS ARTICLE: Kumar VB, Mathias S, Martis JJS. Early postoperative complications of thyroid surgery and their management. J. Evolution Med. Dent. Sci. 2016;5(87):6498-6500, DOI: 10.14260/Jemds/2016/1469

\begin{abstract}
BACKGROUND
Surgery forms the mainstay of treatment of thyroid swellings. Thyroid surgery in the hands of experienced surgeons is currently one of the safest procedures performed. While complications following thyroidectomy are rare, their consequences can often be debilitating and even life threatening when they occur. The major complications include postoperative haemorrhage, wound infection, hypocalcaemia, respiratory obstruction, thyroid storm, hypoparathyroidism and laryngeal nerve injuries. A tension haematoma deep to the cervical fascia is usually due to reactionary haemorrhage from one of the thyroid arteries, occasionally haemorrhage from a thyroid remnant or a thyroid vein may be responsible. This is a rare but desperate emergency requiring urgent decompression by opening the layers of the wound, not simply the skin closure, to relieve tension before urgent transfer to theatre to secure the bleeding vessel. A subcutaneous haematoma or collection of serum may form under the skin
\end{abstract}

Financial or Other, Competing Interest: None.

Submission 14-09-2016, Peer Review 19-10-2016,

Acceptance 25-10-2016, Published 29-10-2016.

Corresponding Author:

Dr. Vinod Kumar B,

Assistant Professor

Department of General Surgery,

Father Muller Medical College,

Mangalore-575002.

E-mail:vinnudoc1998@yahoo.co.in

DOI: $10.14260 /$ jemds/2016/1469 flaps and may need evacuation in the following 48 hours. This should not be confused with the potentially life threatening deep tension haematoma.

Respiratory obstruction- This is very rarely due to collapse or kinking of the trachea (tracheomalacia). Most cases are caused by laryngeal oedema. The most important cause of laryngeal oedema is a tension haematoma. However, trauma to the larynx by anaesthetic intubation and surgical manipulation are important contributory factors, particularly if the goitre is very vascular, and may cause laryngeal oedema without a tension haematoma. Unilateral or bilateral recurrent nerve paralysis will not cause immediate postoperative respiratory obstruction unless laryngeal oedema is also present but it will aggravate the obstruction. If releasing the tension haematoma does not immediately relieve airway obstruction, the trachea should be intubated at once. An endotracheal tube can be left in place for several days; steroids are given to reduce oedema and a tracheostomy is rarely necessary. Intubation in the presence of laryngeal oedema may be very difficult and should be carried out by an experienced anaesthetist. Repeated unsuccessful attempts may aggravate the problem and in a crisis, it is safer to perform a needle tracheostomy as a temporary measure, a large bore $12 \mathrm{G}$ intravenous cannula (Diameter $2.3 \mathrm{~mm}$ ) is satisfactory. Recurrent laryngeal nerve paralysis and voice change, RLN injury may be unilateral or bilateral, transient or permanent. Early routine postoperative laryngoscopy reveals a much higher incidence of transient cord paralysis than is detectable by simple assessment of the integrity of the voice and cough. 
Such temporary dysfunction is not clinically important; however, but voice and cord function should be assessed at the first follow-up 4 weeks postoperatively. An audit of the British Association of Endocrine Surgeons revealed an RLN palsy rate of $1.8 \%$ at 1 month declining to $0.5 \%$ at 3 months for first-time operations. Permanent paralysis is rare if the nerve has been identified at operation. Injury to the external branch of the superior laryngeal nerve is more common because of its proximity to the superior thyroid artery. This leads to loss of tension in the vocal cord with diminished power and range in the voice. Patients, particularly those who use their voices professionally, must be advised that any thyroid operation will result in change to the voice even in the absence of nerve trauma. Fortunately, for most patients the changes are subtle and only demonstrable on formal voice assessment.

Following subtotal thyroidectomy this usually occurs within 2 years; however, there is a small but progressive annual incidence over many years, which is often insidious and difficult to recognise. The incidence is considerably higher than was previously thought and rates of $20-45 \%$ at 10 years have been reported. This results from a change in the autoimmune response, from stimulation to destruction of the thyroid cells. There is a definite relationship between the estimated weight of the thyroid remnant and the development of thyroid failure after subtotal thyroidectomy for Graves' disease. Thyroid insufficiency is rare after surgery for a toxic adenoma because there is no autoimmune disease present. Parathyroid insufficiency, this is due to removal of the parathyroid glands or due to infarction through damage to the parathyroid end artery; often, both factors occur together.

Vascular injury is probably far more important than inadvertent removal. The incidence of permanent hypoparathyroidism should be less than $1 \%$ and most cases present dramatically 2-5 days after operation; however, very rarely the onset is delayed for 2-3 weeks or a patient with marked hypocalcaemia is asymptomatic.

Thyrotoxic crisis (storm), this is an acute exacerbation of hyperthyroidism. It occurs if a thyrotoxic patient has been inadequately prepared for thyroidectomy and is now extremely rare. Very rarely, a thyrotoxic patient presents in a crisis and this may follow an unrelated operation. Symptomatic and supportive treatment is for dehydration, hyperpyrexia and restlessness. This requires the administration of intravenous fluids, cooling the patient with ice packs, the administration of oxygen, diuretics for cardiac failure, digoxin for uncontrolled atrial fibrillation, sedation and intravenous hydrocortisone. Specific treatment is with Carbimazole 10-20 mg 6-hourly, Lugol's iodine 10 drops 8hourly by mouth or sodium iodide $1 \mathrm{~g}$ intravenously. Propranolol intravenously (1-2 mg) or orally (40 mg 6hourly) will block $\beta$-adrenergic effects. Wound infection cellulitis requiring prescription of antibiotics, often by the general practitioner, is more common than most surgeons appreciate. A significant subcutaneous or deep cervical abscess is exceptionally rare and should be drained.

This study intends to assess the occurrence of various postoperative complications following different thyroidectomy procedures and the role of adequate preoperative patient preparation, careful and meticulous surgical technique and early recognition of postoperative complications with the prompt institution of treatment in reducing morbidity and providing the patient with the best chance of a satisfactory outcome.

\section{Aim of Study}

To study occurrence of early postoperative complications of thyroid surgery and their management.

\section{MATERIALS AND METHODS}

The study consisted of 200 patients with thyroid swelling who underwent elective thyroidectomy at Department of General Surgery in Father Muller Medical College, Mangalore. A detailed history was taken from all the patients. A thorough clinical examination along with examination of other systems was performed. Apart from routine laboratory tests, serum calcium, electrolyte, thyroid profile, FNAC, indirect laryngoscopy, ECG, Echo, X-ray Chest and Neck, USG of Neck and CT neck if malignant were performed. Patients who were fit to undergo surgery were included in the study.

The choice of thyroid operation depends on diagnosis, risk of thyroid failure, risk of RLN injury, risk of recurrence, Graves' disease, multinodular goitre, differentiated thyroid cancer. Patients were monitored from time of admission till their $6^{\text {th }}$ postoperative day. The operated specimen was sent for histopathological examination. The different types of surgeries performed were total thyroidectomy, total thyroidectomy with parathyroid autotransplantation, subtotal thyroidectomy, hemithyroidectomy and Dunhill procedure.

\section{RESULTS}

In this study, 200 patients who underwent various thyroid surgeries were studied to look for occurrence of different early postoperative complications. The youngest patient was 22 years old and oldest patient was 72 years old. Maximum no. of complications occurred in the $<30$ years age group (20\%) and the lowest incidence of complications (11.11\%) was noticed in 71-80 years age group as shown in table no. 1 . In our study of total 200 patients, $72 \%$ were female and $28 \%$ male. Incidence of complications was $7.14 \%$ in males, $22.2 \%$ in females as shown in table no 2 . The most common indication for surgery was multinodular goitre in $76 \%$ of cases and most common surgery performed was near total thyroidectomy in $63 \%$ of cases as shown in table no.3 and 4 . The total incidence of complications was $18 \%$ as shown in table 5 .

\begin{tabular}{|c|c|c|c|}
\hline $\begin{array}{c}\text { Age } \\
\text { Group in } \\
\text { Years }\end{array}$ & $\begin{array}{c}\text { No. of } \\
\text { Cases }\end{array}$ & $\begin{array}{c}\text { No. of Cases with } \\
\text { Complications }\end{array}$ & Percentage \\
\hline$<30$ & 20 & 4 & 20 \\
\hline $31-40$ & 44 & 8 & 18.18 \\
\hline $41-50$ & 57 & 10 & 17.54 \\
\hline $51-60$ & 44 & 8 & 18.18 \\
\hline $61-70$ & 26 & 5 & 19.23 \\
\hline $71-80$ & 9 & 1 & 11.11 \\
\hline \multicolumn{4}{|c}{ Table 1. Age wise Incidence of Complications } \\
\hline
\end{tabular}

\begin{tabular}{|c|c|c|c|}
\hline Sex & $\begin{array}{c}\text { No. of } \\
\text { Cases }\end{array}$ & $\begin{array}{c}\text { No. of Cases with } \\
\text { Complications }\end{array}$ & Percentage \\
\hline Female & 144 & 32 & $22.2 \%$ \\
\hline Male & 56 & 4 & $7.14 \%$ \\
\hline Total & $\mathbf{2 0 0}$ & $\mathbf{3 6}$ & \\
\hline \multicolumn{4}{|c|}{ Table 2. Sex wise Incidence of Complications } \\
\hline
\end{tabular}




\begin{tabular}{|c|c|c|c|}
\hline & $\begin{array}{l}\text { No. of } \\
\text { Cases }\end{array}$ & $\begin{array}{l}\text { No. of Cases with } \\
\text { Complications }\end{array}$ & Percentage \\
\hline $\begin{array}{l}\text { Multi- } \\
\text { nodular } \\
\text { goitre }\end{array}$ & 152 & 32 & $21.05 \%$ \\
\hline $\begin{array}{l}\text { Solitary } \\
\text { thyroid } \\
\text { nodule }\end{array}$ & 32 & 0 & 0 \\
\hline Malignancy & 16 & 4 & 25 \\
\hline Total & 200 & 36 & \\
\hline \multicolumn{4}{|c|}{$\begin{array}{c}\text { Table 3. Incidence of Complication with Type of Thyroid } \\
\text { Disorder }\end{array}$} \\
\hline
\end{tabular}

\begin{tabular}{|c|c|c|c|}
\hline $\begin{array}{l}\text { Type of } \\
\text { thyroidectomy }\end{array}$ & $\begin{array}{l}\text { No. of } \\
\text { Cases }\end{array}$ & $\begin{array}{c}\text { No. of } \\
\text { Cases with } \\
\text { Compli- } \\
\text { cations }\end{array}$ & Percentage \\
\hline Total & 12 & 2 & 16.66 \\
\hline Total with MRND & 4 & 2 & 50 \\
\hline Subtotal & 26 & 6 & 23.07 \\
\hline Near-total & 126 & 26 & 20.63 \\
\hline Hemithyroidectomy & 32 & 0 & 0 \\
\hline Total & 200 & 36 & \\
\hline \multicolumn{4}{|c|}{$\begin{array}{l}\text { Table 4. Incidence of Complications with Reference to } \\
\text { the type of Thyroidectomy }\end{array}$} \\
\hline
\end{tabular}

\begin{tabular}{|c|c|c|}
\hline Complication & No. of Cases & Percentage \\
\hline Transient hypocalcaemia & 21 & 12 \\
\hline Transient RLN palsy & 10 & 10 \\
\hline Permanent RLN palsy & 1 & 0.5 \\
\hline Airway obstruction & 4 & 2 \\
\hline Total & 36 & \\
\hline Table 5. Post-operative Complications and their \\
Incidence \\
\hline
\end{tabular}

\section{DISCUSSION}

Complications such as bleeding, hypoparathyroidism and Recurrent Laryngeal Nerve Injury (RLNI) represent nearly half of all the complications of thyroid surgery. ${ }^{1-3}$ The latter complication after thyroidectomy, although infrequently encountered, can jeopardise the quality of life. ${ }^{4}$ The total incidence of complications was $18 \%$ and the most common complication was transient hypocalcaemia in this study i.e. with incidence of $12 \%$ which correlates well with the study of Richmond et al ${ }^{5}$ who noticed an incidence of $13 \%$. Transient RLN palsy which was noticed in 6 patients with incidence of $6 \%$ is more when compared to the studies of Chow et al ${ }^{6}$ who noticed an incidence of $2 \%$. The permanently damaged RLN often manifests as an irreversible dysfunction of phonation and is the most common complication following thyroid surgery. ${ }^{7}$ Permanent recurrent laryngeal nerve palsy which occurred in one patient $(0.5 \%)$ is comparable to study by Hazem M. Zakaria ${ }^{8}$ et al (0.29\%) treated with arytenoidectomy. Other complications like wound infection, wound haematoma and thyroid storm were not seen in this study similar to the studies of Steurer et al $^{9}$ and Erbil et al. ${ }^{10}$ The highest incidence of complications was seen with total thyroidectomy and in multinodular goitre. All the patients with complications were effectively managed and they recovered completely within 3 months period.

\section{CONCLUSION}

It can be concluded that a good understanding of thyroid gland anatomy improved techniques in haemostasis, RLN dissection, preservation of parathyroid glands and postoperative monitoring have caused steady decline in the incidence of postoperative complications following thyroidectomy. In addition, appropriate postoperative care with early identification of complications and prompt institution of corrective treatment plays an important role in reducing the duration of postoperative hospital stay and limiting patient morbidity.

\section{REFERENCES}

1. Ready AR, Barnes AD. Complications of thyroidectomy. $\mathrm{Br}$ J Surg 1994;81(11):1555-6.

2. Friedrich $\mathrm{T}$, Steinert $\mathrm{M}$, Keitel R, et al. The incidence of damage to the recurrent laryngeal nerve in surgical therapy of various thyroid gland diseases-a retrospective study. Zentralbl Chir 1998;123(1):25-9.

3. Filho GJ, Kowalski LP. Surgical complications after thyroid surgery performed in a cancer hospital. Otolaryngol Head Neck Surg 2005;132(3):490-4.

4. Bergamaschi R, Becouarn G, Ronceray J, et al. Morbidity of thyroid surgery. Am J Surg 1998;176(1):71-5.

5. Richmond BK, Eads K, Flaherty S, et al. Complications of thyroidectomy and parathyroidectomy in a rural community hospital setting. Am Surg 2007;73(4):332-6.

6. Chow TL, Chu W, Lim BH, et al. Outcomes and complications of thyroid surgery: retrospective study. Hong Kong Med J 2001;7(3):261-5.

7. Randolph GW, Kobler JB, Wilkins J. Recurrent laryngeal nerve identification and assessment during thyroid surgery: laryngeal palpation. World J Surg 2004;28(8):755-60.

8. Zakaria HM, Al Awad NA, Al Kreedes AS, et al. Recurrent laryngeal nerve injury in thyroid surgery. Oman Med J 2011;26(1):34-8.

9. Steurer M, Passler C, Denk DM, et al. Advantages of recurrent laryngeal nerve identification in thyroidectomy and parathyroidectomy and the importance of postoperative and preoperative laryngoscopic examination in more than 1000 nerves at risk. Larynoscope 2002;112(1):124-33.

10. Erbil $Y$, Barbaros $\mathrm{U}$, Issevr $\mathrm{H}$, et al. Predictive factors for recurrent laryngeal nerve palsy and hypoparathyroidism after thyroid surgery. Clin Otolaryngol 2007;32(1):32-7. 